\title{
ASSESSMENT AND MANAGEMENT OF BEHAVIORAL PROBLEMS IN VASCULAR DEMENTIA
}

\author{
Mariana Arnaoudova \\ Department of psychiatry, Medical University - Varna; Third psychiatric Clinic, \\ University Hospital "St. Marina" - Varna, Bulgaria
}

\section{SUMMARY}

Behavioral disorders in dementia are troublesome and impact the family, caregivers, nursing or hospital staff. A number of strategies have been developed to reduce that burden.

The assessment of demented patients is complicated by the fact that patients are usually unable to express reasons for their feelings and behavior. It is important the type and frequency of behavioral symptoms to be assessed and described and, if possible, the underlying basis of the target symptom to be determined.

In our paper we discuss the most burdensome behavioral symptoms in vascular dementia and on the basis of our knowledge and clinical experience we propose different treatment solutions- pharmacological or non pharmacological. We point out that non- pharmacological solutions are usually applied to milder behavior problems, while others-without environmental triggers, that are severely distressing for caregivers, may require additional pharmacotherapy.

The optimal therapeutic results require knowledge, training and experience with such a group of demented patients.

Key words: behavioral symptoms, vascular dementia, assessment, management

\section{INTRODUCTION}

Vascular dementia $(\mathrm{VaD})$ is one of the most common forms of dementia, ranking only second to Alzheimer's disease. The prevalence of $\mathrm{VaD}$ ranges from 5 to 10 per 1000 and depends on the population studied and use of different diagnostic systems $(1,2,3,4)$. Noncognitive, Behavioral and Psychological Symptoms of dementia (BPSD), are common in $\mathrm{VaD}$. Some symptoms may be similar to those of other types of dementia and usually reflect increasing difficulty to perform everyday activities. Behavioral disorders are troublesome and impact the family, caregivers, nursing or hospital staff. It is important the type and frequency of behavioral symptoms to be assessed and described and, if possible, the underlying basis of the target symptom to be determined.

\section{SUBJECTS AND METHODS}

We examined clinically 68 patients (over 60 years of age) who entered an acute geronto-psychiatric station in order to elicit different types of behavioral problems and propose management solutions. Delirium and dementia were diagnosed according to the criteria of ICD-10 (5) and DSMIV (6). Vascular dementia was diagnosed according to the criteria of NINCDS-AIREN/National institute of Neurological and Communicative Disorders and Stroke/Association Internationale pour la Recherchй et l'Enseignement en Neurosciences/ (7).

\section{RESULTS}

Out of all 68 patients $18(26.47 \%)$ were delirious with manifested psychomotor agitation. The rest 50 patients were diagnosed with probable $\mathrm{VaD}$. A variety of behavioral disorders were present along with that of $\mathrm{VaD}$ patients. Usually multiple symptoms occurred simultaneously. The most often behavioral symptoms met were agitation, verbal and physical aggression, irritability or emotional outbursts, pacing. The presentation of the data according to CohenMansfield subtypes of agitated behavior revealed that verbally- (68\%) and physically-aggressive types (54\%) prevail over verbally- (36\%) and physically non-aggressive behavior (38\%).

\section{DISCUSSION}

We would like to point out some issues that complicate the differentiation between dementia and delirium at initial examination, as the therapeutic approaches are different. The assessment of demented patients is complicated by the fact that patients are usually unable to express reasons for their feelings and behavior. Delirious patients may present with the same BPSD, seen in dementia. Delirium and dementia frequently coexist or their clinical symptoms and etiologies often overlap. As Young and Inouye (8) discuss, new research is needed in this direction. Delirium episode could be a sign of undetected dementia $(9,10,11)$ and predicts poor prognosis $(12)$.

Differential diagnosis of delirium in a cognitively intact patient is comparatively easier and is based on the 
well known criteria: acute onset, fluctuation, altered level of consciousness, inattention, disorientation to time and place, visual hallucinations, accompanied by psychomotor agitation or increased somnolence, altered prosody of speech, sleep-wake cycle disturbances.

Delirium, superimposed on dementia, creates, in number of cases, serious diagnostic difficulties, especially in cross-section examination. Basis for distinguishing at initial assessment and limited information could be unimpaired consciousness and normal level of arousal in dementia. Anamnesis, prior psychiatric history, physical examination, laboratory and instrumental tests would help to detect the underlying reason, provoking delirium. In such a case the next step is to treat underlying medical problem and follow the guidelines of management of delirium state. It includes organizing a secure and comfortable environment, constant observation, reassurance, repeated explanations and information, withdrawal of drugs, supportive care. The administration of psychotropic medicaments is disputable and is limited to low doses of neuroleptics or benzodiazepines for sedation. Our experience is with low dose haloperidol.

In cases with no delirium and a presence of a disruptive behavior in dementia a comprehensive assessment of BBSD should:

- identify the dominant target symptom group;

- identify factors that may influence the behavior;

- assess the frequency and severity;

- suggest adequate management.

According to some studies, associated behavioral symptoms due to agitation, anxiety, psychosis, irritability, hostility, aggression, inversion of circadian rhythm are most troublesome and most difficult problems to manage in patients in dementia $(13,14)$. They are persistent and distressful for caregivers. BPSD could not be fully connected only with the state of severity of dementia. Biological, psychological, environmental factors or premorbid characteristic should be taken into attention. In case of verbal aggression despite dementia we should suspect pain, undetected discomfort, somatic problem (15) or side effect of medication.

In our every day contact and practice we have registered that caregivers' distress is more associated with neuropsychiatric symptoms and problem behavior than the degree of dementia. Taking into account all possible provoking factors we build up our therapeutic strategy. The frequency and severity of behavioral symptoms should be examined in order to organize the adequate psychiatric management, which could be summarized: mild severity of the symptoms requires a non- pharmacological approach, while to moderate and severe presentation pharmacological therapy should be added.

We follow some general principles: Conduct immediate management in a safe, low-stimulation environment. Drugs are applied to calm the person and reduce agitation or aggression and the risk of violence and harm without marked sedation. The lowest effective dose is used, drug combinations to be avoided.

\section{CONCLUSION}

Neuropsychiatric symptoms and problem behavior in patient with vascular dementia could present in different ways. Their assessment presents particular difficulty. Management involves psychological, environmental, behavioral and pharmacological interventions.

\section{REFERENCES:}

1. Rocca WA, Hofman A, Brayne C, Breteler MM, Clarke M, Copeland JR, et al. The prevalence of vascular dementia in Europe: facts and fragments from 1980-1990 studies. EURODEM-Prevalence Research Group. Ann Neurol. 1991 Dec; 30(6): 817-24. [PubMed]

2. Pohjasvaara T, Mantyla R, Ylikoski R, Kaste M, Erkinjuntti T. Comparison of different clinical criteria (DSM-III, ADDTC, ICD-10, NINDSAIREN, DSM-IV) for the diagnosis of vascular dementia. Stroke. 2000 Dec; 31(12):2952-7. [PubMed]

3. Erkinjuntti T, Ostbye T, Steenhuis $\mathrm{R}$, Hachinski V. The effect of different diagnostic criteria on the prevalence of dementia. N Engl J Med. 1997 Dec 4; 337(23):1667-74. [PubMed] [CrossRef]

4. Dimitrov I, Tsourio Ch, Milanov I, Deleva N, Traykov L. Prevalence of Dementia and Mild Cognitive Impairment in a Bulgarian Urban Population. Am J Alzheimers Dis Other Demen. 2012 Mar;27(2):131-135. [PubMed] [CrossRef]

5. World Health Organization: The ICD-10 Classification of Mental and behavioral Disorders: Clinical Descriptions and Diagnostic Guidelines. Geneva: World health Organization, 1992.

6. American Psychiatric
Association Diagnostic and Statistical Manual of Mental Disorders:DSM-IV, 4th edn. Washington, DC: American Psychiatric Association, 1993.

7. Roman GC, Tatemichi TK, Erkinjuntti T, Cummings JL, Masdeu $\mathrm{JC}$, Garcia JH, et al. Vascular dementia: diagnostic criteria for research studies. Report of the NINDS-AIREN International Workshop. Neurology. 1993 Feb;43(2):250-60. [PubMed]

8. Young J, Inouye SK. Delirium in older people. BMJ. 2007 April 21; 334 (7598):842-846. [PubMed] [CrossRef]

9. Rahkonen T, LuukkainenMarkkula R, Paanila S, Sivenius J, Sulkava R. Delirium episode as a sign 
of undetected dementia among community dwelling elderly subjects: a 2 year follow-up study. J Neurol Neurosurg Psychiatry. 2000 Oct; 69(4): 519-21. [PubMed] [CrossRef]

10. Koponen HJ, Riekkinen PJ. A prospective study of delirium in elderly patients admitted to a psychiatric hospital. Psychol Med. 1993 Feb; 23(1): 103-9. [PubMed]

11. Levkoff SE, Evans DA, Liptzin B, Cleary PD, Lipsitz LA, Wetle TT, et al. Delirium. The occurrence and persistence of symptoms among elderly hospitalized patients. Arch Intern Med. 1992 Feb;152(2):334-40. [PubMed]

12. Rockwood K, Cosway S, Carver $\mathrm{D}$, et al. The risk of dementia and death after delirium. Age Ageing. 1999 Oct;28(6):551-6. [PubMed] [CrossRef]

13. Rabins PV. Measuring Quality of Life in Persons with Dementia. Int Psychogeriatr. 2000; 12 /Suppl.1/:47-
49. [CrossRef]

14. Bliwise DL. Circadian Rhythms and Agitation. Int Psychogeriatr. 2000; 12/Suppl.1/: 143-146. [CrossRef] 15. Cohen-Mansfield J. Conceptualization of agitation results based on the Cohen-Mansfield Agitation Inventory and the Agitation Behavior Mapping Instrument. Int. Psychogeriatr. 1996; 8/Suppl 3/:309315. [PubMed]

Address for correspondence

Assoc. prof. Mariana Arnaoudova, MD, PhD

MHAT 'St. Marina”,

1, Hr. Smirnenski str., Varna 9010, Bulgaria

Phone: 00359888512627

E-mail:marnaudova@hotmail.com; 